\title{
Comparing the Effects of Morphine Sulfate and Diclofenac Suppositories on Postoperative Pain in Coronary Artery Bypass Graft Patients
}

\author{
Vali Imantalab ${ }^{1}$; Ali Mirmansouri ${ }^{2, *}$; Abbas Sedighinejad ${ }^{1}$; Bahram Naderi Nabi ${ }^{1}$; Farnoush \\ Farzi ${ }^{1}$; Hadi Atamanesh ${ }^{1} ;$ Nassir Nassiri ${ }^{3}$ \\ ${ }_{2}^{1}$ Anesthesiology Department, Guilan University of Medical Sciences, Rasht, Iran \\ ${ }^{2}$ Anesthesia Research Center, Dr. Heshmat Hospital, Guilan University of Medical Sciences, Rasht, Iran \\ ${ }^{3}$ Cardiac Surgery Department, Guilan University of Medical Sciences, Rasht, Iran \\ *Corresponding author: Ali Mirmansouri, Anesthesia Research Center, Dr. Heshmat Hospital, Guilan University of Medical Sciences, Rasht, Iran. Tel: +98-9111315314, Fax: +98- \\ 1316668718,E-mail:a_mirmansoori@gums.ac.ir \\ Received: April 23, 2014; Revised: May 12, 2014; Accepted: August 18, 2014
}

\begin{abstract}
Background: Simple and efficient way of pain management after Coronary Artery Bypass Graft (CABG) surgery is an important aspect of patients' care.

Objectives: This study aimed to compare the effects of morphine and diclofenac suppositories on postoperative pain management. Patients and Methods: In this double-blinded clinical trial study, 120 patients aged 30-65 years old, undergone CABG, were equally divided into two groups of A (morphine) and B (diclofenac). All patients were anesthetized with intravenous fentanyl $10 \mu \mathrm{g} / \mathrm{kg}$, etomidate $0.2 \mathrm{mg} /$ $\mathrm{kg}$ and cisatracurium $0.2 \mathrm{mg} / \mathrm{kg}$. Anesthesia was maintained with oxygen $50 \%$ and air 50\%, propofol $50 \mu \mathrm{g} / \mathrm{kg} / \mathrm{min}$, fentanyl $1-2 \mu \mathrm{g} / \mathrm{kg} / \mathrm{h}$ and atracurium $0.6 \mathrm{mg} / \mathrm{kg} / \mathrm{h}$. Analgesics were administered after the operation at intensive care unit(ICU)and Visual Analogue Score(VAS) was evaluated in both groups in 4-hour intervals after extubation for 24 hours. After extubation in case of VAS > 3, morphine suppository $10 \mathrm{mg}$ (group A) or diclofenac suppository $50 \mathrm{mg}$ (group B) was administered for patients.

Results: No significant statistical relationship was found between the two groups regarding gender, age, BMI, paracetamol consumption, length of operation time, cardiopulmonary bypass pump (CPB) time, and stay time at ICU(PValue $\geq 0.05$ ). Total dosage of used morphine was $22 \pm 8.3 \mathrm{mg}$ in each patient and total dosage of used diclofenac was $94 \pm 32.01 \mathrm{mg}$. Average variation of VAS at measured intervals was significant (PValue $\leq 0.0001$ ), but these variations were not significantly different when comparing the two groups $(\mathrm{PV}$ Value $=0.023)$. Conclusions: Both morphine and diclofenac suppositories reduced pain significantly and similarly after CABG surgery.
\end{abstract}

Keywords:Cardiac Surgery; Pain; Morphine; Diclofenac

\section{Background}

Coronary artery bypass graft (CABG) is a common procedure in cardiac surgery. Pain management is one of the most important aspects of postoperative management (13). Opening the chest in most patients for CABG requires mid sternotomy. Surgical instruments that expand the chest put pressure on muscles and bones in the operation site. Separating the left internal mammary artery (LIMA) can be extremely painful. Postoperation pain is due to pulling the skeleton muscles or manipulation of parietal pleura, cartilages and periosteum of sternum. In addition, placement of chest tubes at the end of operation can cause postoperative pain. Pain after CABG usually lasts for three days (4). Postoperative pain can stimulate autonomic nervous system resulting in physiological reactions such as increased oxygen consumption of myocardium and myocardial ischemia. Inadequate pain management in ICU can cause restriction of physical movement leading to decreased respiratory activities and undesirable consequences such as pulmonary complication and thrombotic events (5). Pain manage- ment not only provides patient satisfaction, but also is important for physicians because of extra physiological benefits. To control postoperative pain, various nonsteroidal anti-inflammatory drugs (NSAID) and opioids are commonly used. Several routes of drug delivery are used including oral, intramuscular or intravenous injection, transdermal patch, patient control analgesia (PCA) or rectal (5-7). Opioids are generally used during and immediately after the operation. Although, opioids are relatively effective, prescribing high dosages of opioids can cause a series of adverse effects such as itching, sedation, nausea, vomiting, respiratory depression and constipation (8). Some surgical centers prescribe NSAIDs as analgesic agent. Immediately after the operation, short-term prescription of NSAIDs in selected patients has been demonstrated to be effective with relatively low adverse effects $(5,7,8)$. Diclofenac sodium as a NSAID agent has antirheumatic, anti-inflammatory, pain control and some other properties. Despite the fact, it causes platelet, renal and gastrointestinal dysfunction (9). Diclofenac reduces pain and inflammation in surgical site. Diclofenac can be

Copyright (C) 2014, Iranian Society of Regional Anesthesia and Pain Medicine (ISRAPM); Published by Kowsar. This is an open-access article distributed under the terms of the Creative Commons Attribution-NonCommercial 4.0 International License (http://creativecommons.org/licenses/by-nc/4.0/) which permits copy and redistribute the material just in noncommercial usages, provided the original work is properly cited. 
prescribed as 50-100 mg suppository with the maximum dosage of $150 \mathrm{mg}$ per day in two or three divided doses in adults. Quick absorption through rectum has been shown $(10,11)$.

\section{Objectives}

Considering the nothing per oral (NPO) restriction for oral medications in early post extubated patients, and since "Epidural Thoracic Catheter" contradicts anticoagulant medications, it is impossible to use invasive pain control measures. Due to unavailability of intravenous forms of certain medications, specifically NSAIDs, and less "first pass effect" of the suppository form of medications compared to the oral form (3), it was decided to compare suppository forms of morphine sulphate and diclofenac to study and compare their efficacy in controlling patients' pain. In addition to compare pain reduction properties in the both groups, this study aimed to assess undesirable adverse effects in post CABG patients in ICU in the two groups $(12,13)$.

\section{Patients and Methods}

This double blind, randomized, clinical trial was conducted in a teaching hospital after obtaining approval from the Ethical Committee. One hundred and twenty patients, aged 30-65 years, scheduled for elective CABG surgery were enrolled in the study after providing complete verbal information about the study and medications. Furthermore, written informed consent was obtained from all patients. All participants were educated about VAS. The patients were divided into two groups of A (morphine) and B (diclofenac) using random allocation.

Exclusion criteria included:

1) All kinds of cardiac surgery except elective CABG.

2) Consumption of any type of narcotic drugs before the operation.

3) ASA class $>$ III.

4) Allergic history to either of the two drugs.

5) History of liver disease, renal insufficiency, pulmonary disease such as asthma, COPD, and any gastrointestinal disease (active gastritis or bleeding).

6) Ejection fraction $<40 \%$.

In the preoperative visit, all patients were fully examined and premedicated with lorazepam $1 \mathrm{mg}$ the night before the operation and morphine $0.1 \mathrm{mg} / \mathrm{kg}$ one hour prior to transferring to the operating room. Moreover, they were assured of other alternative postoperative pain control options. In the operation room, preliminary anesthetic monitoring was completed (ECG, establishing arterial and central venous line under local anesthesia, pulse oximetry and Near Infra-Red Spectroscopy (NIRS). After recording baseline vital parameters, anesthesia was induced using intravenous fentanyl $10 \mu \mathrm{g} / \mathrm{kg}$, etomidate $0.2 \mathrm{mg} / \mathrm{kg}$ and cisatracurium $0.2 \mathrm{mg} / \mathrm{kg}$. The patients were ventilated manually with $100 \%$ oxygen until tracheal intubation was performed. Thereafter with intermittent positive pressure ventilation (MEDEC, Saturn EVO), the end-tidal Co2 partial pressure was maintained at 35-40 $\mathrm{mmHg}$. Anesthesia was maintained with oxygen $50 \%$ and air $50 \%$, intravenous propofol $50 \mu \mathrm{g} / \mathrm{kg} / \mathrm{min}$, fentanyl $1-2 \mu \mathrm{g} / \mathrm{kg} / \mathrm{h}$ and atracurium $0.6 \mathrm{mg} / \mathrm{kg} / \mathrm{h}$. At the end of the operation, patients were transferred to ICU and underwent mechanical ventilation. Sedation for all patients was performed through IV delivery of propofol $1-3 \mathrm{mg} / \mathrm{kg} / \mathrm{h}$. Approximately 4 hours later, when patients' hemodynamic stabilized, ventilator weaning was initiated. After removing the tracheal tube, VAS was measured every 4 hours for 24 hours or any other time if the patient expressed pain. In the case of VAS $\geq 3$, based on the group A or B, the patients were accordingly given morphine sulfate suppository $10 \mathrm{mg}$ every 8 hours or diclofenac sodium suppository $50 \mathrm{mg}$ (Abureyhan Drug Manufacturing, Iran) every 8 hours. Anesthesiologist responsible to monitor patients was blinded to the type of drugs, but to consider possible adverse effects, anesthesiologist staff was aware of this. Nursing staff were given complete training to use suppository in the rectum (neither in the anal canal nor in the feces). Preventative measures were taken to ensure that proper treatment is provided if any side effect occurs. Adverse effects were treated as follows: pruritus with chlorpheniramine $10 \mathrm{mg}$ IV, nausea and vomiting with ondansetron $4 \mathrm{mg}$ IV, respiratory depression (respiratory rate less than $8 / \mathrm{min}$ ) with naloxone 0.08 microgram IV, hypotension (blood pressure decrease more than $20 \%$ of the baseline) with normal saline $5 \mathrm{~mL} / \mathrm{kg} / 20 \mathrm{~min}$ and dyspepsia with pantoprazole 40 mg each 12 hours. At the first 24 hours of the study, each 8 hours, when patients' pain did not decrease (VAS $>3$ ), paracetamol (Apotel, Cobeldaru of Iran) with a dosage of $1000 \mathrm{mg}$ added to $50 \mathrm{~mL}$ normal saline, was infused in 30 minutes through IV. When pain persisted, morphine 0.05 $\mathrm{mg} / \mathrm{kg}$ ) was prescribed, and he or she was excluded from the study.

\subsection{Statistical Analysis}

Analysis was performed using SPSS version 19 software (an IBM company, USA) to compare the two groups. To compare VAS levels in the two groups when VAS levels followed a normal distribution, Paired T test was used. To compare median of changes of VAS in the both groups, Independent T-test was used. When VAS levels did not follow a normal distribution in each group, RM ANOVA was used and to compare changes in VAS level in each group before and after prescribing suppositories, Mann-Whitney test was used. $\mathrm{P} \leq 0.05$ was considered statistically significant.

\section{Results}

This study was performed on two groups of 60 patients. One group received morphine suppository, and the other diclofenac suppository. Of all patients, 52.5\% were male and $47.5 \%$ were female. Using Fisher's exact test, there were no significant statistical differences between male 
Imantalab Vet al.

and female patients who received morphine suppository or diclofenac suppository $(\mathrm{P}<0.855)$ (Table 1$)$. Patients' demographic information was presented in Table 1. Among all patients, 76.7\% had CBP time over 60 minutes and $23.3 \%$ of the patients had CBP time less than 60 minutes. By using Fisher's exact test, no significant differences in CBP time were seen between the two groups $(\mathrm{P}=0.829)$ (Table 2). Duration of operation in $48.3 \%$ of patients was less than 2.5 hours and in $51.7 \%$ was more than 2.5 hours. Fisher's exact test showed no significant differences in the duration of operation between the two groups who received morphine and diclofenac suppository $(\mathrm{P}>0.05)$ (Table 2). In total, $65 \%$ of patients were intubated for less than 8 hours and 35\% more than 8 hours in ICU. By using fisher's exact test, no significant differences in intubation time at ICU were found between the two groups ( $P$ $=0.848)($ Table 2$)$.

At first in morphine and diclofenac groups, mean values of VAS were 5.85 and 5.18, respectively. These amounts gradually decreased to 2.45 and 2.43 , respectively after 24 hours of VAS measurement. Changes in VAS values were approximately similar in the both groups in each time. By using General linear model and repeated measurement, there were significant statistical differences between measured VAS $(\mathrm{P}<0.0001, \mathrm{~F}=39.32)$ in the group A. Likewise, there were significant statistical differences between the values of measured VAS in the group $\mathrm{B}(\mathrm{P}<$ $0.0001, F=33.43$ ) (Figure 1). In the both groups, significant variations were found in the values of VAS in different periods (intra-group) (Table 3). Variations in VAS averages at different periods did not show significant statistical results $(P=0.203, F=1.45)$ in the both groups using general linear model and repeated measurement. It means that average VAS variations in different periods in both groups were not noticeably different and approximately similar (Table 3, indicator 1).

Paracetamol was used once in some patients and 2 or 3 times in some other patients. A small group of patients did not receive paracetamol to relief pain (Table 4). In all patients, pain did not persist after administration of intravenous paracetamol. Therefore, no one needed intravenous morphine in addition to paracetamol. By using Chi-square test, no significant statistical association was found between the groups of A and B when Paracetamol was administered after the removal of chest tube $(\mathrm{P}=$ 0.595). In morphine group, 14 (9\%) patients experienced some adverse effects. Two patents (3\%) had pruritus, treated with chlorpheniramine $10 \mathrm{mg}$, and four patients (6\%) had nausea treated with ondansetron $4 \mathrm{mg}$ IV. There was no adverse effect in diclofenac group. Considering the limitations of using these drugs within a 24-hour period, supplementary use of Paracetamol injection with the dosage of $1000 \mathrm{mg}$ every 8 hours could help manage patients' pain, between suppository prescription intervals. Statistical results indicated no meaningful differences in the number of times that Paracetamol was administered to the both groups.

\begin{tabular}{|c|c|c|c|c|}
\hline Group & Morphine & Diclofenac & Total & PValue \\
\hline Gender & & & & 0.855 \\
\hline Male & $31(51.7)$ & $32(53.3)$ & $63(52.5)$ & \\
\hline Female & $29(48.3)$ & $28(46.7)$ & $57(47.5)$ & \\
\hline Age, $y$ & & & & 0.917 \\
\hline Younger than 50 & $13(21.7)$ & $12(20)$ & $25(20.8)$ & \\
\hline $50-60$ & $31(51.7)$ & $30(50)$ & $61(50.8)$ & \\
\hline Older than 60 & $16(26.7)$ & $18(30)$ & $34(28.2)$ & \\
\hline BMI, $\mathrm{kg} / \mathrm{m}^{2}$ & & & & 0.431 \\
\hline Less than 19 & $2(3.3)$ & $0(0)$ & $2(1.7)$ & \\
\hline $19-25$ & $17(28.3)$ & $22(36.7)$ & $39(32.5)$ & \\
\hline $25-30$ & $29(48.3)$ & $27(45)$ & $56(46.7)$ & \\
\hline More than 30 & $12(20)$ & $11(18.3)$ & $23(19.2)$ & \\
\hline Total & $60(100)$ & $60(100)$ & $120(100)$ & \\
\hline
\end{tabular}

${ }^{\mathrm{a}}$ Abbreviation: BMI, body mass index.

Table 2. Relative Frequency Rate of Cardiopulmonary Bypass Time, Duration of Operation and Intubation Time in ICU Patients in the Two Groups (Morphine and Diclofenac) ${ }^{a}$

\begin{tabular}{|c|c|c|c|c|}
\hline Group & Morphine & Diclofenac & Total & P Value \\
\hline CPB time & & & & 0.829 \\
\hline Less than 60 min & $13(21.7)$ & $15(25)$ & $28(23.3)$ & \\
\hline $\begin{array}{l}\text { More than } 60 \\
\text { min }\end{array}$ & $47(78.3)$ & $45(75)$ & $92(76.7)$ & \\
\hline
\end{tabular}

\begin{tabular}{|c|c|c|c|c|}
\hline $\begin{array}{l}\text { Duration of op- } \\
\text { eration }\end{array}$ & & & & 1.0 \\
\hline Less than $2.5 \mathrm{~h}$ & $29(48.3)$ & $29(48.3)$ & $58(48.3)$ & \\
\hline More than $2.5 \mathrm{~h}$ & $31(51.7)$ & $31(51.7)$ & $62(51.7)$ & \\
\hline $\begin{array}{l}\text { Intubation time } \\
\text { In ICU }\end{array}$ & & & & 0.848 \\
\hline Less than $8 \mathrm{~h}$ & $40(66.7)$ & $38(63.3)$ & $78(65)$ & \\
\hline More than $8 \mathrm{~h}$ & $20(33.3)$ & $22(36.7)$ & $42(35)$ & \\
\hline $\begin{array}{l}\text { Total in each } \\
\text { Group }\end{array}$ & $60(100)$ & $60(100)$ & $120(100)$ & \\
\hline
\end{tabular}

a Abbreviation: $\mathrm{CPB}$, Cardiopulmonary bypass.

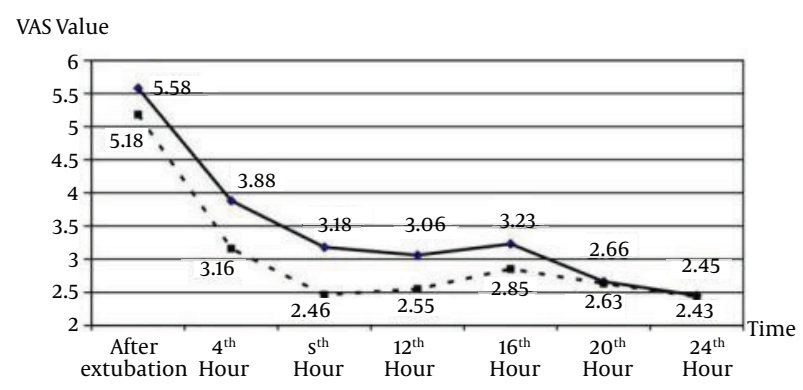

Figure 1. Comparison of Visual Analogue Score Changes, Measured in Different Times, in Morphine and Diclofenac Groups 
Imantalab Vet al.

\begin{tabular}{|c|c|c|c|c|c|c|}
\hline Time & Number of Patients & Mean \pm SD & $\mathbf{F}$ & P value in Each group & $\mathbf{F}$ & P value Between groups \\
\hline Morphine & & & & 0.0001 & 1.45 & 0.203 \\
\hline After extubation & 60 & $5.58 \pm 1.8$ & 35.13 & & & \\
\hline 4th hour & 60 & $3.38 \pm 1.71$ & & & & \\
\hline 8th hour & 60 & $3.18 \pm 1.55$ & & & & \\
\hline 12th hour & 60 & $3.06 \pm 1.42$ & & & & \\
\hline 16th hour & 60 & $3.23 \pm 1.33$ & & & & \\
\hline 20th hour & 60 & $2.66 \pm 1.08$ & & & & \\
\hline 24th hour & 60 & $2.45 \pm 0.92$ & & & & \\
\hline Diclofenac & & & 37.74 & 0.0001 & & \\
\hline After extubation & 60 & $5.18 \pm 1.83$ & & & & \\
\hline 4th hour & 60 & $3.16 \pm 1.32$ & & & & \\
\hline 8th hour & 60 & $2.46 \pm 0.87$ & & & & \\
\hline 12th hour & 60 & $2.55 \pm 0.99$ & & & & \\
\hline 16th hour & 60 & $2.85 \pm 1.16$ & & & & \\
\hline 20th hour & 60 & $2.63 \pm 1.04$ & & & & \\
\hline 24th hour & 60 & $2.43 \pm 0.85$ & & & & \\
\hline
\end{tabular}

Table 4. Times of Paracetamol Administration in Morphine and Diclofenac Groups

\begin{tabular}{lcccc}
\hline Times of Paracetamole Administration & Morphin Supp., No. (\%) & Diclofenac Supp., No. (\%) & Total, No. (\%) & P value \\
\hline No need & $9(15)$ & $6(10)$ & $15(12.5)$ & 0.595 \\
Once & $28(46.7)$ & $32(53.3)$ & $60(50)$ & 0.595 \\
Twice & $20(33.3)$ & $21(35)$ & $41(34.2)$ & 0.595 \\
Three times & $3(5)$ & $1(1.7)$ & $4(3.3)$ & 0.595 \\
Total & $60(100)$ & $60(100)$ & $120(100)$ & 0.595 \\
\hline
\end{tabular}

\section{Discussion}

Effective pain management is necessary to help stimulating adequate breathing efforts and to reduce myocardial ischemic events in post CABG patients. This is essential for patients' comfort, also warrants physicians' achievement for better physiological outcome $(4,5,7)$. Effective pain management is especially important for post CABG patients in ICU, because it can prevent a number of adverse effects, resulting in a shorter stay in ICU, patients' satisfaction, and a smaller economic burden $(1,14)$. Morphine Sulfate is a narcotic analgesic for controlling moderate to severe pain. Diclofenac sodium, as an NSAID, can also decrease inflammation and alleviate moderate to severe pain due to surgical manipulation $(8,12,15,16)$. In this study, these two drugs were compared to determine their efficacy on post CABG surgery pain. In sonography guided study conducted by Haswir et al. effects of oral morphine and diclofenac suppository on pain management in prostatic biopsy were compared; no meaningful differences were found between the two drugs for pain alleviation (3), which is similar to our study. It could be concluded that morphine and diclofenac reduce pain similarly regardless of the route of administration. In the study conducted by Kulik and colleagues, effectiveness of Naproxen was examined to reduce pain in post CABG patients in ICU. Ninety-eight patients were divided into two groups. One group received Naproxen and the other group placebo. The study showed that Naproxen reduced pain during four postoperative days. They also reported some adverse effects such as nausea, emesis and dyspepsia in diclofenac suppository group $(\mathrm{P}=0.034)(15)$. In our study, no adverse effects were found in diclofenac suppository group. This difference could be due to the duration of using naproxen in Kulik's study. We used diclofenac for 24 hours. In the study conducted by Khan, diclofenac efficacy was assessed to manage pain and reduce narcotic dosage in post cardiac surgery. Their result indicated that diclofenac suppository together with Tramadol was ideal for post cardiac surgery (6). Besides, use of diclofenac and Tramadol together, reduced the dosage of used Tramadol resulting in less narcotic adverse effects. Goushe et al. conducted a study comparing paracetamol and opioids for reducing pain after laparoscopic cholecystectomy. 
They mentioned that paracetamol caused better pain relief than opioid in case of mild pain, but paracetamol could not control pain as well as opioid in acute phase after the operation (17). We had similar results in morphine and diclofenac groups. Paracetamol is a weak analgesic compared to diclofenac (morphine was common in the both studies). In Jazayeri et al. study, the effect of intraarticular administration of morphine and tramadol was assessed after arthroscopic knee surgery. They found that these two drugs significantly decreased pain with the maximum effect at six-hour postinjection. Based on the results of our study, morphine suppository could relief pain after CABG. It seems that morphine can reduce postoperative pain effectively regardless of the route of administration (11). This study showed that using either of the suppository drugs, morphine sulfate or diclofenac sodium, in post-surgery CABG patients in ICU, can be effective in pain control. No meaningful differences were found between the two groups. Given the facts, both of these drugs could be prescribed for pain management, and if one group is contraindicated or accompanied with undesirable adverse effects, the other one can be substituted.

\subsection{Limitations}

Most patients with coronary artery disease have concurrent illnesses, and some of them consume opioids regularly to reduce chest pain. Besides, some patients need emergency CABG surgery. Therefore, all issues mentioned above took time for allocating samples needed for this study.

\section{Acknowledgements}

The authors would like to gratitude Guilan University of Medical Sciences and Heshmat Hospital staff for their cooperation.

\section{Authors' Contributions}

Vali Imantalab: study design, conduct of study, data interpretation, and obtaining funding; Ali Mirmansouri: conduct of study, administrative technical and scientific revision of the manuscript; Abbas Sedighinejad: literature search and analysis; Bahram Naderi Nabi: data interpretation and clinic analysis; Farnoush Farzi: data interpretation and critical revision of the manuscript; Hadi Atamanesh: study design, data collection and manuscript preparation; Nassir Nassiri: conduct of study and data interpretation.

\section{Funding/Support}

The research presented in this manuscript was funded by Guilan University of Medical Sciences' thesis grants.

\section{References}

1. Barnason S, Zimmerman L, Nieveen J, Schulz P, Miller C, Hertzog $\mathrm{M}$, et al. Relationships between fatigue and early postoperative recovery outcomes over time in elderly patients undergoing coronary artery bypass graft surgery. Heart Lung. 2008;37(4):245-56.

2. Woods A, Brull DJ, Humphries SE, Montgomery HE. Genetics of inflammation and risk of coronary artery disease: the central role of interleukin-6. Eur Heart J. 2000;21(19):1574-83.

3. Haswir H, Umbas R. Comparison of efficacy between oral morphine sulphate and diclofenac suppository for analgesia during transrectal ultrasound-guided prostate biopsy. Acta Med Indones. 2008;40(3):124-8.

4. Immer FF, Immer-Bansi AS, Trachsel N, Berdat PA, Eigenmann $\mathrm{V}$, Curatolo M, et al. Pain treatment with a COX-2 inhibitor after coronary artery bypass operation: a randomized trial. Ann Thorac Surg. 2003;75(2):490-5.

5. Hynninen MS, Cheng DC, Hossain I, Carroll J, Aumbhagavan SS, Yue R, et al. Non-steroidal anti-inflammatory drugs in treatment of postoperative pain after cardiac surgery. Can J Anaesth. 2000;47(12):1182-7.

6. Hussain AM, Khan FA, Sheikh L. Effect of diclofenac suppository on tramadol consumption in posthysterectomy pain.J Coll Physicians Surg Pak. 2008;18(9):533-7.

7. Oberhofer D, Skok J, Nesek-Adam V. Intravenous ketoprofen in postoperative pain treatment after major abdominal surgery. World J Surg. 2005;29(4):446-9.

8. Dhawan N, Das S, Kiran U, Chauhan S, Bisoi AK, Makhija N. Effect of rectal diclofenac in reducing postoperative pain and rescue analgesia requirement after cardiac surgery. Pain Pract. 2009;9(5):385-93.

9. Mireskandari SM, Makarem J. Effect of rectal diclofenac and acetaminophen alone and in combination on postoperative pain after cleft palate repair in children. J Craniofac Surg. 2011;22(5):1955-9.

10. van Hoogdalem E, de Boer AG, Breimer DD. Pharmacokinetics of rectal drug administration, Part I. General considerations and clinical applications of centrally acting drugs. Clin Pharmacokinet. 1991;21(1):11-26.

11. Jazayeri SM, Mosaffa F, Abbasian M, Hosseinzadeh HR. Comparing the efficacy of intra-articular application of morphine and tramadol on postoperative pain after arthroscopic knee surgery. Anesth Pain Med. 2012;2(1):28-31.

12. Tuzuner AM, Ucok C, Kucukyavuz Z, Alkis N, Alanoglu Z. Preoperative diclofenac sodium and tramadol for pain relief after bimaxillary osteotomy. J Oral Maxillofac Surg. 2007;65(12):2453-8.

13. Pettersson PH, Jakobsson J, Owall A. Intravenous acetaminophen reduced the use of opioids compared with oral administration after coronary artery bypass grafting. J Cardiothorac Vasc Anesth. 2005;19(3):306-9.

14. Vosoughin M, Mohammadi S, Dabbagh A. Intravenous ketamine compared with diclofenac suppository in suppressing acute postoperative pain in women undergoing gynecologic laparoscopy. J Anesth. 2012;26(5):732-7.

15. Kulik A, Ruel M, Bourke ME, Sawyer L, Penning J, Nathan HJ, et al. Postoperative naproxen after coronary artery bypass surgery: a double-blind randomized controlled trial. Eur J Cardiothorac Surg. 2004;26(4):694-700.

16. Bottiger BA, Esper SA, Stafford-Smith M. Pain management strategies for thoracotomy and thoracic pain syndromes. Semin Cardiothorac Vasc Anesth. 2014;18(1):45-56.

17. Gousheh SM, Nesioonpour S, Javaher Foroosh F, Akhondzadeh R, Sahafi SA, Alizadeh Z. Intravenous paracetamol for postoperative analgesia in laparoscopic cholecystectomy. Anesth Pain Med. 2013;3(1):214-8. 